\title{
Global Health and Health Diplomacy
}

The "short" 20th century, as defined by Eric Hobsbawm, was marked by major economic, social, scientific, and technological progress that improved both quality of life and health conditions around the world. Still, in an "age of extremes", to use Hobsbawm's same definition, globalization also created growing international disparities, producing enormous social and health problems, particularly in the countries most excluded from the global economy's central circuits. Declining health conditions in large contingents of the population, food insecurity, and climate changes have raised increasing concerns in the international community.

Through various initiatives that serve what are often contradictory interests, the United Nations, agencies of international cooperation from developed countries and some emerging nations, and international philanthropy have approached health as a priority on the international cooperation agenda and in development aid programs. This process has been called "global health diplomacy", that is, the set of negotiations at various levels that define and manage the setting for global health policies and that - ideally - produce better population health results in each country (thus serving the national interests), as well as implementing relations between states and bolstering the commitment by a wide range of stakeholders in pursuit of a common undertaking to ensure health as a human right and a public good (Kickbusch I, et al. Bull World Health Organ 2007; 85:230-2). A key example is the Millennium Development Goals (http://www.un.org/millenniumgoals), a series of commitments set by the United Nations Millennium Summit in 2000.

Global health and health diplomacy require new institutional and professional public health mechanisms, thus leading various academic institutions around the world to establish research and training centers dedicated to the issue. A recent example in Brazil was provided by the Oswaldo Cruz Foundation, which created the Fiocruz Center for Global Health (CRIS) in January 2009 with the aim of further consolidating the foundation's extensive international cooperation in the health field.

As an emerging global power among the middle-income countries, Brazil has played an outstanding role in health diplomacy in the context of South-South cooperation through what we have referred to as "structuring cooperation in health" (Almeida C, et al. Global Forum Update on Research for Health. Volume 6: Innovating for the Health of All, 2009; p. 199207), which consists of supporting the development and reinforcement of social and health systems by means of structuring institutions in the key health and human resources training systems, as central strategies for organizing the developing countries' own capabilities.

Another Brazilian foreign policy strategy focuses on the establishment of regional blocs, where health has been a central priority. Examples include UNASUL-Health (http://www. unasur-salud.org) in the Union of South American Nations and CPLP-Health (http://www. cplp.org/Saúde.aspx?ID=353) in the Community of Portuguese-Speaking Countries.

This Editorial thus aims to highlight the emergence of "global health" and "health diplomacy" as areas in foreign policy and international cooperation and as an academic and human resources training field that can be expected to grow substantially in the coming decade around the world and specifically in Brazil, to the extent that international solidarity succeeds in overcoming predatory competition between nations.

Paulo Marchiori Buss

Director, Center for International Relations in Health (CRIS).

Oswaldo Cruz Foundation, Rio de Janeiro, Brazil.
Maria do Carmo Leal

Vice President of Teaching, Information, and Communication,

Oswaldo Cruz Foundation, Rio de Janeiro, Brazil. 